\title{
PSYCHOBIOGRAPHY: UNDERSTANDING CONCEPTS, STEPS, AND PROCEDURES IN THE STUDY OF LIVES
}

\author{
Sefa Bulut, Ali Cissy Usman \\ Ibn Haldun University, Turkey \\ E-mail: sefabulut22@gmail.com, alicissey.usman@ibnhaldun.edu.tr
}

\begin{abstract}
The process of applying psychological theories to examine the biographical and autobiographical data of famous individuals is what is termed "psychobiography". Since its inception in the early sixteenth century, this qualitative type of research method has had a fairly storied history in the Western world. This study provides a clear picture of psychobiographical research by defining terms and phrases that are used in relation to psychobiographical research. It also covered its historical antecedent and steps and procedures that are necessary for undertaking psychobiographical research. The steps presented here stemmed from a broad phase in qualitative research and analysis. In practice, however, psychobiographies do not always adhere to systematic formats, but some key decisions and guidelines must be followed in order to ensure the trustworthiness of the study's findings. Thus, the research mainly aims at introducing psychobiography, and life history research to the reader.
\end{abstract}

Keywords: psychobiography, life history research, qualitative methods in psychology

\section{Introduction}

Once upon a time, most psychologists in the field considered psychobiography to be a fairy tale story with little or no scientific standing to present a vivid and clear understanding of human behaviors. However, recent narratives have seen an upsurged importance among researchers in the autobiographical collections, personal narratives, and life stories of famous and outstanding individuals in order to better understand human behaviors and experiences. The rationale behind this is that in the current global society, where people have experienced many challenges, it is therefore significant to examine the past and its exceptional figures in order to understand contemporary societies (Chéze, 2010). That being the case, the investigation of such individuals goes beyond mere psychodiagnostic classification. For instance, it will be inadequate to view all serial killers as individuals with antisocial personalities (Chéze, 2010), rather it will be more insightful to view the individual in a more holistic manner. A matter that will be able to explore and describe the individuality that underlies and intensifies the crime committed. This, therefore, is the aim of psychobiography as a qualitative research method.

As a matter of fact, researchers in the field of psychology in recent times have encouraged students to conduct clinically relevant and ethically sound psychobiographical studies of significant 
individuals (Ponterotto, 2015; Ponterotto \& Reynolds, 2017). Thus, psychobiography has become a more insightful method of re-understanding and reinterpreting individual lives (Fouchè et al., 2007; Fouchè \& van Niekerk, 2005). As a result, this study is set against the backdrop that humans are naturally biographical creatures, by providing a vivid understanding of psychobiography research methods. Firstly, it provides a clear definition of psychobiography with terms and phrases that are used in different studies that relate to psychobiography. This is followed by a succinct but informative historical overview of psychobiography as a research method. Finally, concepts, theories, steps, and procedures in the realm of conducting psychobiographical research are discussed.

\section{Research Methodology}

The framework for conducting this study is based on the viewpoint held by systematic reviews. Therefore, the procedures used across the various stages of this study are conducted stringently and clearly. To this end, the researchers started with the question: What is known in the existing literature about psychobiography, life history, and life story research? This defined the kinds of parameters to be included in the study. Moreover, since psychobiography is a qualitative research method that cuts across disciplines such as psychology, sociology, history, art, and political science, we decided to maintain a wide approach in order to generate different kinds of literature on the subject. To achieve this, we opted for a search strategy that involved searching for evidence in electronic databases such as Google Scholar, PubMed, and PsycINFO, as well as electronic books and reference lists of previous studies with the keywords "psychobiography", "psychohistory", "life story" and "life history research".

From that point, we initially opted to include those studies and books published between 1999 to date. This is because we felt that major psychobiography, life story, and life history studies in recent times started gaining momentum in 1999. However, this generated a large number of relevan and irrelevant studies. We, therefore, needed to develop inclusion and exclusion criteria based on the aims and objectives of the study to eliminate studies that did not answer our central questions. The inclusion criteria were studies that related to the history, importance, steps, and theories used in psychobiography research. Those articles and studies were read to make the final decision on whether or not they should be included in the study. Having read all the articles and studies, those that were deemed important to be included in the study were solely due to their relevance to the study's aims and objectives.

\section{Definition}

Humans are by nature biographical animals. As storytellers, humans differ from other creatures not only in anticipating their individual and societal future, but in reviewing and recounting their personal pasts.

Humans are by nature biographical animals. As storytellers, humans differ from other creatures not only in anticipating their individual and societal future, but in reviewing and recounting their personal pasts.

Humans are by nature biographical animals. As storytellers, humans differ from other creatures not only in anticipating their individual and societal future, but in reviewing and recounting their personal pasts.

Throughout the history of psychology, researchers have studied lives and human behaviors in diverts ways and forms. In all such studies, terms such as biography research, life story research, and psychobiography have been used as methodological themes to explain fundamental theoretical underpinnings that are critical to the understanding of the research design (Lapan et al., 2012). By definition, psychobiography is a thorough life-span study of historical figures in a socio-cultural frame of reference incorporating psychological and historiographic research methodology through a psychological theoretical lens (Ponterotto, 2015a). This means that psychobiography is a crossdisciplinary effort that integrates the study of the human mind with the study of human life. In some studies, it has also been described as life narratology, case study, life history, personality psychology, or psychological biography. Regardless of the term used, the primary objective of 
such a study is to pursue for and produce incisive explanations of an individual's life history using a full breadth of psychological theories. For this reason, according to Mayer and Kovary (2019), Vol. 15, No. 1, 2021 psychologists and counselors who provide psychotherapy and counseling are largely regarded as psychobiographers rather than natural scientists because they rely on human behaviors, fantasies, dreams, notes, and dialogues to decipher their meanings in relation to the individual.

In such a research method, what differentiates it from other methods is the application of psychological theory as a lens through which an individual life is viewed. The application of psychological theory is to gain a deeper exploration of the inner world of the individual (Mayer, \& Kovary, 2019; Kovary, 2019) by penetrating beneath that of which the individual portrays to others and that of which the individual is uninformed in themselves (Mayer, \& Kovary, 2019). This aids in comprehending and explaining the motivations underlying some of the individual's actions and decisions.

\section{Historical Overview of Psychobiography}

It is important to note that due to increased interest in recent times (Fouché, 2015), psychobiographies have emerged as a thriving field of psychology (Köváry, 2011). However, its origins can be traced back to the early twentieth century, when Sigmund Freud published the first written psychobiography titled "Leonardo da Vinci and a Memory of His Childhood," in 1910 (Mayer \& Kovary, 2019). This resulted from a meeting by the Vienna Psychoanalytic Society, which did believe that pathography couldn't offer any new real insightful evidence on the examinations of individuals (Köváry, 2011) because the style was largely an attempt to overemphasize on the negative aspects of a person's life. An aspect that includes unhappiness, illness, tragedy, and failures. In a critical examination of Freud's psychobiography of Leonardo da Vinci, Köváry (2011) noted that the essay established a new approach in psychology. An approach that portrays something about Leonardo da Vinci's childhood from a narrative of his infant experience with a bird, from which Freud viewed his childhood fantasy based on the memory of sucking his mother's nipple through the lens of psychosexual development.

Even before then, Kőváry (2011) has drawn attention to the works of Plutarch (45-125 AD) on the lives of artists in the sixteenth century as a historical antecedent that gave birth to the later work of Sigmund Freud. But in those early works of Plutarch, there were hardly any applications of psychological concepts and theories to analyze and interpret the subject's lives (McAdams, 2006a, 2006b) which is a critical and essential feature of psychobiography. It was therefore Freud's work that pioneered psychological standpoint in life history or life story research. Following Freud's introduction, psychobiography studies quickly gained popularity from the 1910s to the 1930s (Schultz, 2005) mostly among psychoanalysts. According to Köváry (2011), approximately 300 psychobiography studies within the framework of psychoanalytical approaches were published during that period. Despite its enormous popularity at the time, such a research method was criticized for its strong ties to psychoanalysis (Ponterotto, 2015b). Other critics of the method also centered around the fact that psychobiography lacked internal validity because it was possible to find alternative explanations to human behavior products outside the use of psychoanalytic lenses (Ruiters, 2013).

This led to it not been used as a research method in the 1940s until the early 1950s (Köváry, 2011) through to the 1970s (Perry, 2012). A period when psychobiography was no longer limited to psychoanalytic theories, as well as a time that also witnessed the introduction of personology approach; an attempt to explore peoples' lives through their life stories (Jareño et al., 2019). The emphasis in all of those attempts has always been on the fact that life stories appear to be the only means by which individual individualities can be discovered, as when people talk about personality, the theme has always centered on the individual's life story. On these grounds, Erikson's later works emphasized the importance of bridging the gap between psychology and history. This according to Köváry (2011) therefore signifies the invention of psychohistory. An approach that resides broadly within the frame of narrative approaches, autoethnography, biography, cultural biography, oral history, and life story (Tierney, \& Clemens, 2012).

Since then, psychobiography has become a popular scientific research method that cuts across 
OF PSYCHOLOGY

IN THE $21^{\text {st }}$ CENTURY

Vol. 15 , No. 1,2021

10

disciplines such as psychiatry, psychology, sociology, anthropology, politics, literature, religion, and history (Carducci, 2009). A growth that is attributed largely to the frustration of quantitative data struggling to uncover and express life experiences (Mayer, 2017). As of today, numerous psychobiographical studies have been conducted on politicians, religious leaders, actors, serial killers, psychologists, artists, and others (Eliastram, 2011; Fouché et al., 2017) that have had a local and worldwide impact on societies (Köváry, 2011).

\section{Related Concepts Associated with Psychobiography}

To understand the scientific approach to psychobiography, its concepts need to be distinguished from other related research concepts. Psychobiographies, according to Köváry (2011), are components of psychoanalytic approaches, personality psychology, and creativity research. This is influenced by the historical antecedents to psychobiography. An antecedent that is influenced by literature and psychology, life philosophy, and pathography (Köváry, 2011). For these reasons, different cross-disciplinary concepts like autobiographies, life histories and life stories, historical psychology, life narratives, psychohistories, and case studies all have close relationships with psychobiographic research (Schultz, 2005; McAdams, 2006a).

In the psychobiographical study of Anton Boisen, Kramp (2012) proposed that autobiographies are used to study and draw conclusions from individual life stories and experiences. More keenly, the style and fashion in such a write-up portray interpretations of life and what one saw as unresolved issues of his or her life. For this reason, autobiographies are sometimes placed within the corridors of life history research. Life history research allows us to investigate a person's historical individual experience in relation to a particular historical time. Hence, the relationship between psychobiography and autobiographies and the differences between psychobiography and life history stems from the fact that psychobiographical research relies on data from autobiographical collections for content analysis and interpretation (Smith, 2014). Whereas life history focuses on relationships across multiple lives compared to psychobiographies that are mostly interested in one single life (Mayer, 2017). In a nutshell, life history research pursues to uncover differences and similarities in the lifestyles of multiple individuals, whilst psychobiographies pursue to uncover the uniqueness of a single individual life. To this aim, both life history, and psychobiographic research approaches refer to biographic details to formulate meaningful conclusions within a well-informed cultural context (Mayer, 2017).

Regarding psychohistory and psychobiography, both approaches define themselves as independent research mythologies (Mayer, 2017). The approach in psychohistory is often a diffusion of psychology and history (Schultz, 2005). It primarily employs psychoanalytic principles to investigate the "why" of history. Therefore, when a study is free of historical perspectives and does not over-rely on psychoanalytic approaches, it cannot be decided as psychohistory.

In addition, it is equally paramount to consider the relationships and the difference that exists between life narratives and psychobiography as well as case study research and psychobiography. Even though life narrative approach might be closely linked to psychobiography, the two are still distinct from each other (Schultz, 2005). Life narrative to a large extent is based on text and stories, which is often disregarded as reality (Schultz, 2005). For this reason, it has long been emphasized that the study of life narratives has more to do with oral or written accounts, which are mostly influenced by subjective viewpoints and narrative abilities (Schultz, 2005). Whereas psychobiography is more structured and therefore proposes to discuss something real rather than friction. Nevertheless, both two approaches have become popular in recent times in the quest of studying life meanings.

With case studies, the focus is directed to finding the why and how of a subject situation (Yin, 2009). Psychological case studies are aimed at taking account of specific changes that occur in reaction to a method (Fouché \& Van Niekerk, 2005). For example, in a typical psychological case study, captivating records of key events, experiences, and circumstances, at specific times are documented. Interpretations are therefore made based on such key records rather than considering the totality of the entire individual life. To this, the difference between case studies and 
psychobiographies is based on the fact that one gives more importance to specific life events and between all the aforementioned approaches to psychobiographies, all rely on personal diaries, letters, biographies, and autobiographies to define the individual.

\section{Theories Used in Psychobiographies}

As previously stated, the use of psychological theories via which an individual as a subject of study is understood is what distinct psychobiographies from other methods. Thereupon, previous guidelines on psychobiographic studies have all emphasized on theory selection as a crucial part of any psychobiographical study (see, Ponterotto, 2015a; Du Plessis, 2017). Thus, the quality of any psychobiographical study is often determined by the theory used, and the researcher's knowledge and understanding of the theory. This has led to certain theories been dominant in psychobiographical studies compared to others. For example, psychoanalytic (Kőváry, 2011) and psychodynamic theories (Ponterotto, 2014, 2015a). In those theoretical perspectives, most of the theories used are John Bowlby's attachment theory (Kelley, 2019), Sigmund Freud's theory of childhood behavior (Ponterotto et al., 2015), and Donald Woods Winnicott's theory of object relation (Verwey \& Knight, 2019).

Notwithstanding the dominance of those theories, one theory that has also gained popularity in psychobiographies in recent times is Erik Erikson's eight-stage psychosocial development (Ruiters 2013; Marx, 2015). Besides, as research on wellness and wellbeing has increased, researchers have emphasized the application of positive psychology across studies and psychobiographical analysis (Mayer \& Van Zyl 2013; Seligman, 2011; Mayer, 2017; Ponterotto 2015b). To this extent, one of the central concepts of positive psychology; the neo-Adlerian holistic wellness model (neoAdlerian HWM) has also been well applied to psychobiographical studies (Burnell, 2013; Fouché et al., 2015). Most notably in the psychobiography of Brenda Fassie (see. Nortjé et al., 2013), and in the psychobiography of Paulo Coelho (see. Mayer (2017).

Admittedly, a variety of theoretical paradigms are now available for today's psychobiographers. It is therefore important to consider the cultural context in which a psychobiographic study covers before choosing a theory to analyze lives (Anderson \& Dunlop, 2019). In the same line, it is equally important in considering the socio-cultural context in selecting a suitable psychobiographical research topic (Burnell et al., 2019). As the topic and the analysis, all are expected to fit within the cultural context of the study. This is when the intercultural competencies and cultural sensitivity of the researcher come to play. The researcher must not just select a subject and a theoretical lens from which to analyze findings but must be willing to tolerate ambiguities and be ready to change perspectives with respect to cultural differences (Mayer, 2011). This in many views helps to avoid cultural bias and deepen the understanding of life in a cultural context.

\section{Conducting A Psychobiographic Study}

In all forms of research, aligning to a particular philosophical worldview or approach is critical to the success of the research. This is because they provide answers regarding the most basic question of life. Psychobiography from its ancient days used idiographic approaches (Mayer, 2017; Fouché \& Van Niekerk 2010). The idiographic approach spotlights the individual and emphasizes the individual uniqueness of persons based on their worldliness experience and human nature. The aim of idiographic approach is not to formulate a generalization of findings but to achieve a thematic analysis that allows for an in-depth understanding of an individual. However, according to Mayer (2017), today's psychobiographers fall within hermeneutic perspectives. Because in the views of Schultz (2005) supported by Köváry, (2011), psychobiographical authors are often regarded as individuals who attempt to explore and interpret text psychologically.

It, therefore, made sense to approach psychobiography from a philosophical perspective that involves cultivating the ability to understand things from someone else's point of view (hermeneutics) while appreciating the influence of culture and the uniqueness of the individual (idiographic). Furthermore, most psychobiographic research turns to deploy qualitative research approaches. 
Where the researcher selects a qualitative research framework as a research design by focusing to analyze the meanings individuals attach to their experiences, beliefs, and emotions (Lapan et al., 2012). This focus means the researcher is deciding to adopt a constructivist worldview. A worldview that gives importance to how individuals create subjective meanings to their experiences within a socio-cultural context (Lapan et al., 2012). However, psychobiographical researchers sometimes do rely on a research design that includes the use of a quantitative approach. This is when a researcher incorporates quantitative data collection into their psychobiography or biography research studies (Lapan et al., 2012).

After the psychobiography researcher has settled on the worldview and research design to deploy, Elms (2007) outlined steps such as: choosing the research subject, formulation of hypotheses, initial data collection, review of previous hypotheses, increased data collection, resolving discrepancies in data sources, use of itinerary analysis, making a valid conclusion, and a call for a further itinerary study on the subject as critical phrases that need to be dealt with accordingly. In a more unified form, Schultz (2005) also categorized these steps into; reading about the subject from first-person and third-person documents, locating a mystery to unveil, re-reading documents of the mystery, and building the story. However, we do believe in substances, it is Miles et al., (2014) 12 steps in any qualitative study that outline systematically the necessary steps in psychobiographical studies. These steps include:

\section{Subject Selection}

This is a process that involves settling on the historical figure that the researcher considers as important and necessary to conduct a psychobiography study on. Factors to be considered at this initial first step have to do with the researcher's relationship with the intended subject, its symbolic importance, ethical considerations (subject living or dead), and the availability of written or oral information about the subject (Ponterotto, 2014). According to Du Plessis (2017), evaluating the researcher's relationship with the subject and its significance guides in understanding the motivations behind the study as well as in the formulation of precise questions that the researcher wishes to explore. Whereas ethical considerations assist in determining whether such a study will be harmful to the subject if they are alive or their families if they are deceased (Du Plessis, 2017). This, therefore, implies that the ability to provide coherent answers to these questions denotes the appropriateness of the psychobiographical study. In most psychobiographical subject selections, psychobiographers rely on purposive or theoretical sampling (Köváry, 2011), because what to sample is chiefly based on the researcher's own interest.

\section{Identification Of Primary and Secondary Source Materials to The Subject}

To produce an insightful psychobiography, it is important to assess and read adequate available materials in both first-person and third-person documents about the subject (Schultz, 2005). First-person documents of the subject are often found in the subject's biographies, autobiographies, diaries, obituaries, magazine articles, creative works, and life histories. In addition, surviving relatives of the subject may be an important source for retrieving thirdperson documents. This includes archival formal materials as well as a willingness to share a well-intended psychobiography of the subject (Robins et al., 2007). It is therefore important to collect and maintain a large chain of evidence on the subject before proceeding to interpret psychologically. This allows access to the strengths and limitations of these materials, which aids in resolving potential bias in the interpretation.

\section{Identifying The Subject's Living Environment}

Every life is often encircled by socio-cultural materials and these materials manifest themselves directly and indirectly in many respects. This means that the life of the subject under any psychobiography study is heavily influenced by local and international sociopolitical, religious, historical, and cultural factors. Even though the psychobiographer is not necessar- 
ily expected to be an expert in every cultural background, it deemed it important to gather sufficient local cultural information to ensure the influences of these factors are rightly Vol. 15, No. 1, 2021 included in the psychobiography (Du Plessis, 2017). One useful tool in this regard is the Multi-Layered Chronological Chart (MLCC) developed by Hiller (2011) for biography. The chart shows the relationship between the subject's personal life and the various and diverse socio-cultural environments to which he or she is exposed to. Previous psychobiographical studies like that of Ponterotto and Reynolds (2013) and Ponterotto (2013) all have demonstrated the usefulness of Hiller's (MLCC) tool to facilitate an all-inclusive understanding of a subject within a socio-cultural, religious, political context.

\section{Theory Selection}

Logically, the quality of every psychobiography study depends among other things on the selection of an appropriate theory. The general consensus is that the choice of theory should be based on the theory's ability to best highlight the characteristics of the subject's life that is valuable to the psychobiographer (Du Plessis, 2017). Furthermore, when selecting a theory, the psychobiographic researcher needs to think thoroughly through the various dispositions of theories. In the same fashion, it is important to know that while some psychological theories are classified as grand theories (e.g., psychoanalytic theory and psychosocial theory), and emergent theories (e.g., Vygotsky's sociocultural theory), others are classified as mini theories that are only interested in exploring specific domains of individual functioning. A grand theory is only necessary when the researcher is interested in thoroughly examining the complete life of the subject; otherwise, other theories aimed at examining specific domains of functioning are deemed necessary (Du Plessis, 2017).

\section{Allowing The Data to Speak for Itself}

This step falls within Elms (2007) outline stage of resolving discrepancies in data sources. According to Robins, Fraley et al., (2007), it is quite common to encounter inconsistency when dealing with diverse biographic data from multiple sources. These inconsistencies may be minor or major, relating to differences in date of birth or date of death, childhood experiences, work-life, and issues of faith and beliefs. To resolve these contradictions and inconsistencies, the psychobiographer needs to de-construct the existing narrative to allow the psychological evidence to prevail (Du Plessis, 2017), or by developing rationales for trusting or disagreeing with specific sources of information. Moreover, such issues may be avoided by focusing exclusively on primary sources of data, such as the subject's own oral and written documents; however, this may not be completely accurate because the subject may be interested in sharing only what he or she believes to be the truth but not the absolute truth.

\section{Asking Specific Questions with The Data at Hand (Formulating Hypothesis)}

Every psychobiographer begins a study with likely hypotheses and questions which he or she wants to unravel. These questions and hypotheses may solely be in the interest of the researcher or the general public. Some writers of psychobiographies suggested that it is indeed better to start formulating research questions and hypotheses after a thorough collection of data on the subject because only then will the researcher know exactly what questions to ask (e.g., Du Plessis, 2017). Regardless of when the psychobiographer begins formulating hypotheses and research questions, what matters is that the hypotheses must be ready to provide answers to questions that are speculative on the subject. Similarly, questions to ask must also stem from the theory that will be deployed. By doing this, the researcher is establishing a systematic approach that will ensure the trustworthiness of the study.

\section{Coding Strategies and Coding Accordingly}

Findings from qualitative studies do not emanate from text themselves; rather, they require 
reasoning to spot key elements in order to come up with coherent stories that answer the research questions (Miles et al., 2013). Codes are therefore used to structure and analyze the data in a structured manner. In psychobiographies, the decisions on how to code and what to code have a significant impact on the final structure of the findings (Miles et al., 2014). Traditional, the ideal way of coding involves relying on the data set. This includes creating codes from the phrases and terms found in the various data sources of the subject, rather than using the researcher's vocabularies and themes. In many views, with that, codes stick close to the ideas of the data by reflecting what is genuinely in them.

\section{Selection of Display Formats}

When organizing findings, the first thing to also consider is how the findings are going to be presented to the readers. The presentation format can have an impact on the study's findings and raise awareness of important issues in the study. Thus, the presentation format must organize the story in a logical manner that makes sense to the readers. There are numerous approaches to presenting psychobiography findings. For instance, using text by grouping large sections of text into headings or incorporating formats such as graphs, tables, and figures (Miles et al., 2014).

\section{Integrating Coding with Display Format}

After deciding on a display format and coding, the focus shifts to integrating the codes into the display format. At this point, it is critical to refer back to previous steps, particularly steps 5 and 6 , where the researcher formulated the research questions and hypotheses. Because it helps in organizing the information in a way that outlines the areas of interest.

\section{Write The Psychobiography}

This is usually the stage whereby the psychobiographer puts all the pieces of the study together. It is also the stage where the creative endeavor of the researcher comes to play. This process should only begin after the researcher has rigorously manipulated and analyzed the data, but in some instances, more new evidence and key information may be required during the write-up (Du Plessis, 2017). In writing, the psychobiographer is expected to start with a clear introduction; by describing the subject, outlining what made them special and why a psychobiographical study on them is important. The introduction should also state and describe the psychological theories that will be applied to the subject. It is important to know that the quality of this stage largely depends on background work during data collection and the creative writing ability of the psychobiographer.

\section{Review of the Psychobiography}

With the fact that psychobiographical studies lack statistical value to point to the truth, it is therefore important for the psychobiographer to evaluate their research based on whether the findings answered their research question. Furthermore, the researcher is expected to reexamine their conclusion on the subject, to see if there are any other alternative explanations to the subject behavior than what they considered. In doing so, specific personal feelings that may influence their interpretation regarding the psychobiographical subject may be resolved.

\section{Evaluation of The Research}

According to Robins et al., (2007), the final scrutiny to determine if a psychobiographical study has been duly conducted is a call for an iterative process by other researchers. To them, when psychobiographical studies are compiled, it is up to the readers or the reviewers to determine which interpretations are best supported by the available facts. Besides, to ensure the trustworthiness of any psychobiographical study, Nel (2013) has highlighted various 
strategies that could be deployed during the research process to ensure the trustworthiness of the study's findings. This includes ensuring a well understanding of the subject's history and Vol. 15, No. 1, 2021 socio-cultural context, following established guidelines for data sorting, and coding, aiming for analytical generalization rather than statistical generalization, using a family member of the subject as an informant on the final draft as well acknowledging that all findings are speculative. In other studies, guidelines such as admitting limitations of the psychobiographical research, clearly defining methods of data sorting and reduction, recognizing possible bias, and being aware of cross-cultural issues are all cited as possible means by which psychobiographical studies can be evaluated (Yin, 2009; Miles et al., 2014).

\section{Conclusions and Implications}

Several methodological considerations must be addressed by psychobiographical researchers in the study of lives. And the steps for undertaking psychobiographical studies have been defined differently by different authors. However, the most important include the selection of subjects and theories, methods of data collection, and analytical strategies. Besides, the advantage of modern psychobiographies is that theory selection is more flexible today than it was centuries ago when psychobiographical studies were heavily influenced by psychoanalysis theories. To end with, psychobiographical research has become an extremely useful approach in the practical examination of self and others. More psychobiographical studies on single and multiple lives in the future will prepare professionals in the helping relationship to better deepening their understanding of the meanings people associate with their life experiences.

\section{References}

Anderson, J. W., \& Dunlop, W. L. (2019). Executing psychobiography. In C.-H. Mayer \& Z. Kovary (Eds.), New trends in psychobiography (pp. 11-33). Springer: Switzerland.

Burnell, B. (2013). The life of Beyers Naudé: A psychobiographical study. Unpublished doctoral thesis, University of the Free State, South Africa.

Burnell, B., Nel, C., Fouché, P. J. P., \& van Niekerk, R. (2019). Suitability indicators in the study of exemplary lives: Guidelines for the selection of the psychobiographical subject. In C.-H. Mayer \& Z. Kovary (Eds.), New trends in psychobiography (pp. 173-193). Springer: Switzerland.

Carducci, B. J. (2009). The psychology of personality (2nd ed.). Wiley.

Chéze, E. (2010). Jeffrey Lionel Dahmer: A psychobiographical study (Doctoral dissertation).

Du Plessis, C. D. (2017). The method of psychobiography: Presenting a step-wise approach. Qualitative Research in Psychology, 14(2), 216-237. https://dx.doi.org/10.1080/14780887.2017.1284290

Eliastram, L. M. (2011). A psychobiography of Archbishop Emeritus Desmond Mpilo Tutu. Unpublished mini dissertation, Magister Artium in Counselling Psychology, Department of Psychology, Fort Hare.

Elms A. C. (2007). Psychobiography and case study methods. In: Robins, R. W., Fraley, R. C., Krueger, R. F. (Eds.), Handbook of research methods in personality psychology (pp. 97-113). Guildford Press.

Fouché, J. P. (2015). The 'coming of age' for Southern African psychobiography. Journal of Psychology in Africa, 25(3), 375-378.

Fouché, J. P., \& van Niekerk, R. (2005). Psychobiography: An interdisciplinary approach between psychology and biography in the narrative reconstruction of personal lives. Conference presentation, Nelson Mandela Metropolitan University.

Fouché, J. P., \& van Niekerk, R. (2010). Academic psychobiography in South Africa: Past, present and future. South African Journal of Psychology, 40(4), 495-507.

Fouché, J. P., Burnell, B., \& \& van Niekerk, R. (2015). The spiritual wellness of Beyers Naudé: A psychobiographical study of a South African anti-apartheid theologian. Journal of Psychology in Africa, 25(5), 429-237. 
Fouché, J. P., Smit, R., Watson, M. B., \& Van Niekerk, R. (2007, August). Psychobiographical research in South Africa: A systematic review from 1995 to 2004. In The Annual South African Psychology Congress.

Fouché, P. J., Rogers, J., \& Naidoo, P. (2017). A psychobiography of Robert Handsen: The Butcher- Baker. Pan African Psychology Congress, ICC, Durban.

Hiller, P. T. (2011). Visualizing the intersection of the personal and the social context--the use of multi-layered chronological charts in biographical studies. Qualitative Report, 16(4), 1018-1033.

Jareño Gómez, A., Chiclana Actis, C., \& Noriega García, C. (2019). Qualitative methodology: Psychobiography. Psychology Psychotherapy Research Studies, 3(1). https://doi.org/10.31031/PPRS.2019.03.000555

Kelley, J. L. (2019). "I have to be all things to all people": Jim Jones, nurture failure, and apocalypticism. In C.-H. Mayer \& Z. Kovary (Eds.), New trends in psychobiography (pp. 363-379). Springer.

Kőváry, Z. (2011). Psychobiography as a method. The revival of studying lives: New perspectives in personality and creativity research. Europe's Journal of Psychology, 7(4), 739-777.

Kovary, Z. (2019). Psychobiography, self-knowledge and "Psychology as a Rigorous Science": Explorations in epistemology, clinical practice and university education. In New trends in psychobiography (pp.99113). Springer.

Kramp, J. M. (2012). Anton Boisen: A portrait. Journal of Religion and Health, 51(2), 450-459.

Lapan, S. D., Quartaroli, M. T., \& Riemer, F. J. (2012). Qualitative research: An introduction to methods and designs. Jossey-Bass.

Marx, M. (2015). Margaret Hilda Thatcher: A psychobiographical study. Unpublished master's dissertation, Nelson Mandela Metropolitan University, Port Elizabeth, South Africa. http:// vital.eals.ac.za:8080/vital/access/manager/Repository/vital:20616/SOURCE1?view

Mayer, C. H. (2011). The meaning of sense of coherence in trans-cultural management. Münster, Germany: Waxmann.

Mayer, C. H. (2017). The life and creative works of Paulo Coelho: A psychobiography from a positive psychology perspective. Springer.

Mayer, C. H., \& Kovary, Z. (Eds.). (2019). New trends in psychobiography. Springer. https://doi.org/10.1007/978-3-030-16953-4

Mayer, C.-H., \& Van Zyl, L. (2013). Perspectives of female leaders on sense of coherence and mental health in an engineering environment. South African Journal of Industrial Psychology, 39(2), http://dx.doi.org/10.4102/sajip.v39i2.1097

McAdams, D. P. (2006a). The person: A new introduction to personality psychology (4th ed.). Wiley.

McAdams, D. P. (2006b). The role of narrative in personality psychology today. Narrative Inquiry, 25, 11-18.

Miles, M. B., Huberman, A. M., \& Saldaña, J. (2014). Qualitative data analysis: A methods sourcebook (3rd Ed.). Sage publications.

Miles, Matthew B, A Michael Huberman, \& Saldaña, J. (2013). Qualitative data analysis: A methods sourcebook. SAGE Publications.

Nel, C. (2013). The life of Helen Suzman: A psychobiographical study. Doctoral dissertation, University of the Free State, Bloemfontein, South Africa.

Nortjé, N., Fouché, P., \& Gogo, O. (2013). The neo-Adlerian holistic wellness of Brenda Fassie: A psychobiography. Online Journal of African Affairs, 2(3), 46-53.

Perry, M. J. (2012). The life of Olive Schreiner: A psychobiography. Doctoral thesis, University of the Free State, Bloemfontein, South Africa.

Ponterotto, J. (2014). Best practices in psychobiographical research. Qualitative Psychology, 1(1), 77-90. https://doi.org/10.1037/qup0000005

Ponterotto, J. G. (2013). Case study in psychobiographical ethics: Bobby Fischer, world chess champion. Journal of Empirical Research on Human Research Ethics. https://doi.org/10.1525/jer.2013.8.4.19 
Ponterotto, J. G. (2015). Psychobiography in psychology: Past, present, and future. Journal of Psychology in Africa, 25(5), 379-389.

Ponterotto, J. G. (2015a). A counsellor's guide to conducting psychobiographical research. International Journal of Advances in Counselling, 39, 249-263. https://doi.org/10.1007/s10447-017-9295x

Ponterotto, J. G. (2015b) Psychobiography in psychology: Past, present and future. Journal of Psychology in Africa, 25(5), 379.

Ponterotto, J. G., \& Reynolds, J. D. (2013). Bobby Fischer in socio-cultural perspective: Application of Hiller's (2011) Multi-Layered Chronological Chart Methodology. Qualitative Report, 18(42).

Ponterotto, J. G., Reynolds, J. D., Morel, S., \& Cheung, L. (2015). Psychobiography training in psychology in North America: Mapping the field and charting a course. Europe 's Journal of Psychology, 11(3). https://doi.org/10.5964/ejop.v11i3.938

Ponterotto, J. G., \& Reynolds, J. D. (2017). Ethical and legal considerations in psychobiography. American Psychologist, 72(5), 446-458. https://doi.org/10.1037/amp0000047

Robins, R. W., Fraley, R. C., \& Krueger, R. F. (2007). Handbook of research methods in personality psychology. Guilford Press. London.

Ruiters, J. J. (2013). Michael Jackson: A psychobiography. Unpublished master's dissertation, Rhodes University, Grahamstown, South Africa. https://core.ac.uk/download/pdf/145047706.pdf

Schultz, W. T. (2005). Handbook of psychobiography. Oxford University Press.

Seligman, M. E. P. (2011). Flourish: A visionary new understanding of happiness and well-being. Free Press.

Smith, M. F. (2014). "Suicidal Mania" and flawed psychobiography: two discussions of Virginia Woolf. English Studies, 95(5), 538-556.

Tierney, W. G., \& Clemens, R. F. (2012). The uses of life history. In S. Selamont (Ed.), Handbook of qualitative research in education (pp. 256-280). Edward Elgar Publishing.

Verwey, L., \& Knight, Z. G. (2019). In search of self: How channel became coco to the world. In C.-H. Mayer \& Z. Kovary (Eds.), New trends in psychobiography (pp. 343-362). Switzerland.

Yin, R. K. (2009). Case study research: Design and methods (4th ed.). Thousand Oaks, CA: Sage.

Cite as: Bulut, S., \& Cissy Usman, A. (2021). Psychobiography: Understanding concepts, steps, and procedures in the study of lives. Problems of Psychology in the $21^{\text {st }}$ Century, 15(1), 7-17. https://doi.org/10.33225/ppc/21.15.07

\begin{tabular}{cl}
\hline Sefa Bulut & PhD, Professor, Department of Guidance and Counseling Psychology, Ibn \\
(Corresponding author) & Haldun University, Istanbul, Turkey. \\
& E-mail: sefabulut22@gmail.com \\
& ORCID: https://orcid.org/0000-0002-2622-4390 \\
\hline \multirow{2}{*}{ Ali Cissy Usman } & Department of Guidance and Counseling Psychology, Ibn Haldun University, \\
& Istanbul, Turkey. \\
& E-mail: alicissey.usman@ibnhaldun.edu.tr \\
& ORCID: https://orcid.org/0000-0002-4578-6655 \\
\end{tabular}

